\title{
Bond strength of different bracket bonding materials to the enamel subjected to thermal cycling ${ }^{1}$
}

\author{
Resistência de união de diferentes materiais de colagem de bráquetes ao esmalte submetidos à ciclagem \\ térmica
}

Alcir ROSOLEN²

Enrico Coser BRID| ${ }^{3}$

Roberta Tarkany BASTING ${ }^{4}$

\section{ABSTRACT}

\section{Objective}

The aim of this study was to evaluate in vitro the shear bond strength of metallic orthodontic brackets to enamel using different bonding materials followed by thermal cycling.

\section{Methods}

A fluid composite resin (Transbond XT / 3M Unitek) and a resin-modified glass ionomer (Fuji Ortho LC I GC America Inc.) were evaluated. Eighty sound human premolars were randomly divided into eight experimental groups $(n=10)$, according to the material used and the number of thermal cycles: zero, 1000, 2000 and 3000 cycles. Bracket bonding was performed on the buccal surface of the teeth. After 24 hours, they were subjected to thermal cycling at temperatures ranging between $5^{\circ} \mathrm{C}$ and $55^{\circ} \mathrm{C}$ for 15 seconds each immersion. Shear bond strength was performed using a universal testing machine with a chisel-type tip at a speed of $0.5 \mathrm{~mm} / \mathrm{min}$. The bond strength data was analyzed using two-way ANOVA.

Results

No difference on shear bond strength was observed regarding the number of thermal cycles for each specimen $(p=0.873)$. A significant difference was found in shear bond strength between the bonding materials $(p=0.022)$, with significantly higher values for Transbond XT regardless of the number of thermal cycles.

\section{Conclusion}

The number of thermal cycles did not significantly affect the bond strength of the adhesive materials investigated. The bonding agent Transbond $X T$ showed higher bond strength than Fuji Ortho LC regardless of the number of thermal cycles.

Indexing terms: Glass ionomer cements. Resin cements. Shear bond strength.

\section{RESUMO}

\section{Objetivo}

Avaliar in vitro a resistência de união por cisalhamento de bráquetes ortodônticos metálicos ao esmalte utilizando diferentes materiais para colagem em função da quantidade de ciclos térmicos.

\section{Métodos}

Foram avaliados um sistema de união com resina composta fluida (Transbond XT/3M Unitek) e um ionômero de vidro modificado por resina (Fuji Ortho LC/GC America Inc.). Oitenta pré-molares humanos hígidos foram aleatoriamente divididos em oito grupos experimentais ( $n=10$ ), de acordo com os tipos de material e quantidade de ciclos térmicos: zero, 1000, 2000 e 3000 ciclos. A colagem dos bráquetes foi realizada na face vestibular dos dentes. Após 24 horas, foram submetidos à ciclagem térmica com temperaturas de imersão entre $5^{\circ} \mathrm{C}$ e $55^{\circ} \mathrm{C}$ por 15 segundos. Os testes de resistência de união foram feitos em máquina de ensaios universal com ponta tipo cinzel com velocidade de 0,5 mm/ min. Os dados foram submetidos à ANOVA a dois critérios.

\section{Resultados}

Não houve diferença na resistência de união entre bráquetes e o esmalte em função do número de ciclos térmicos $(p=0,873)$. Houve diferença significativa na resistência de união proporcionada entre os materiais para colagem $(p=0,022)$, sendo que valores significativamente superiores foram obtidos com a utilização do Transbond XT, independentemente do número de ciclos térmicos.

\section{Conclusão}

A quantidade de ciclos térmicos não influenciou significativamente a resistência de união dos materiais. Transbond XT mostrou maior resistência de união do que o cimento Fuji Ortho LC, independentemente da quantidade de ciclos térmicos.

Termos de indexação: Cimentos de lonômeros de vidro. Cimentos de resina. Resistência ao cisalhamento.

\footnotetext{
${ }^{1}$ Article based on a doctoral thesis: Enamel bond strength of different bracket bonding materials subjected to thermal cycling. Faculdade São Leopoldo Mandic, 2014. 67 p.

${ }^{2}$ Faculdade São Leopoldo Mandic, Curso de Odontologia, Programa de Pós-Graduação em Ortodontia. Campinas, SP, Brasil.

${ }^{3}$ Faculdade São Leopoldo Mandic, Curso de Odontologia, Programa de Pós-Graduação em Clínicas Odontológicas - área de concentração em Dentística. Campinas, SP, Brasil.

${ }^{4}$ Faculdade São Leopoldo Mandic, Faculdade de Odontologia, Departamento de Dentística e Materiais Dentários. Rua José Rocha Junqueira, 13, Swift, 13045-755, Campinas, SP, Brazil. Correspondência para / Correspondence to: RT BASTING. E-mail: <rbasting@yahoo.com>.
} 


\section{INTRODUCTION}

High flow composite resins are among the most widely used materials for bonding orthodontic appliances, due to a combination of uncomplicated clinical applicability as well as their low viscosity (flow type resins), which allows penetration of the material into the etched enamel and the bracket mesh'1. However, they have a high modulus of elasticity and may cause high polymerization shrinkage stress and bond failures ${ }^{1}$, in addition to being susceptible to the moisture present in the oral cavity².

Glass ionomer cement is also a material used for bonding orthodontic brackets. It features both chemical bonding to enamel as well as anticariogenic properties, in addition to being easily removed from the enamel surface, therefore preventing damage ${ }^{3}$. In order to facilitate clinical application and handling, resin components were added to the material, resulting in the so-called resin-modified glass ionomer cement, which shows more favorable clinical outcomes when compared to conventional glass ionomer ${ }^{4}$.

Regardless of the material used for bonding, one should consider several factors that can lead to bond failure of orthodontic brackets to enamel, thus increasing the duration of the treatment, potential damage to the enamel surface and increased chair time due to the need for repeated procedures ${ }^{5-6}$. Among these factors, there are some that can influence bond strength at the time of bonding of the brackets to enamel - etching time, application of the adhesive system and curing time ${ }^{1}$ as well as factors inherent to the oral cavity, such as $\mathrm{pH}$ variations, incident masticatory stress, the patient's own occlusion and its sliding mechanics ${ }^{7}$.

Bond strength must be high enough to provide bracket stability throughout the course of orthodontic treatment; although towards the end of treatment, such property may no longer be so important due to lighter forces, considering that the final movements are aimed at leveling the teeth within the dental arch. It should be considered that any material present in the oral cavity for a long period of time may have lost some of its mechanical properties due to imbibition, solubility and fatigue, thus reducing bond strength and introducing the need for further visits to reattach the appliances at this stage ${ }^{8}$.

In laboratory tests, thermal cycling is used to simulate the normal aging experienced by materials in clinical practice, by subjecting them to repeated temperature fluctuations in hot and cold water and reproducing the thermal changes that occur in the oral cavity ${ }^{7,9-10}$. Although several studies have evaluated the bond strength of brackets bonded to enamel immediately or within the first few hours or weeks after bonding to enamel ${ }^{1,5,11-12}$, there are only a few studies ${ }^{7,13-15}$ that have investigated the effect of bonding material aging in terms of the number of thermal cycles on the bond strength and fracture mode, thus suggesting the need for further studies on this matter. Therefore, the objective of this study was to evaluate in vitro the effect of the number of thermal cycles on the shear bond strength and fracture mode of metallic orthodontic brackets bonded to enamel using either a composite resin or a resin-modified glass ionomer bonding system.

\section{METHODS}

This study was approved by the Research Ethics Committee of the São Leopoldo Mandic Dental School and Research Center (registration number 2012/0031). Eighty sound human upper and lower permanent premolars donated by the teeth bank of the São Leopoldo Mandic Dental School were used. Prophylaxis was performed on the coronal aspect of the teeth using rubber cups (KG Sorensen, Barueri, São Paulo, Brazil) and pumice (extra fine pumice stone, SS White, Rio de Janeiro, Rio de Janeiro, Brazil) and water for 10 seconds at low speed.

The teeth were embedded using standard cylindrical PVC molds (PVC tubes, Tiger, Joinville, Brazil). The latter were positioned vertically and filled with colorless acrylic resin (Vipi Flash, Pirassununga, Brazil) manipulated according to the manufacturer's directions and immediately poured into the PVC pipe. The tooth root was completely immersed into the resin, leaving the buccal surface of the tooth at a right angle with the horizontal plane. Once the acrylic resin was polymerized, a mark was made on the central area of the buccal surface of each tooth to optimize accuracy when bonding the brackets.

The materials used in the study, composition and / or specification, manufacturer and batch number are shown in Chart 1. The brackets were bonded following etching with $37 \%$ phosphoric acid for 15 seconds, rinsing with distilled water for 15 seconds and drying with compressed air for 5 seconds. 
Chart 1. Materials used, composition and / or specification, manufacturer, batch number.

\begin{tabular}{|c|c|c|c|}
\hline Materials & Composition / Specification & Manufacturer (city, state, country) & Batch number \\
\hline $\begin{array}{l}\text { Composite resin } \\
\text { (Transbond XT) }\end{array}$ & $\begin{array}{c}\text { Primer: camphorquinone, TEGDMA, Bis-GMA } \\
\text { Composite resin: Bis-GMA, silane, } \\
\text { n-dimethylbenzocaine, phosphorus hexafluoride, silica }\end{array}$ & $\begin{array}{l}\text { 3M Unitek (Monrovia, California, } \\
\text { United States of America) }\end{array}$ & $\begin{array}{l}\text { Primer: } 712-034 \\
\text { Resin: } 182301\end{array}$ \\
\hline $\begin{array}{l}\text { Resin-modified glass } \\
\text { ionomer (Fuji Ortho LC) }\end{array}$ & $\begin{array}{l}\text { Net: polyacrylic acid, HEMA, UDMA, water } \\
\text { Powder: glass aluminosilicate }\end{array}$ & $\begin{array}{l}\text { GC America Inc., (Alsip, Illinois, } \\
\text { United States of America) }\end{array}$ & 1003161 \\
\hline Phosphoric acid (Condac) & $37 \%$ phosphoric acid & $\begin{array}{c}\text { FGM (Joinville, Santa Catarina, } \\
\text { Brazil) }\end{array}$ & 68059 \\
\hline $\begin{array}{l}\text { Metal bracket Abzil } \\
\text { Kirium Line Roth }\end{array}$ & Stainless Steel & $\begin{array}{l}\text { Abzil Ind. E Com. Ltda (São José } \\
\text { do Rio Preto-SP-Brazil) }\end{array}$ & 1111800272 \\
\hline
\end{tabular}

The materials for orthodontic bonding were handled according to the manufacturer's standards. For the composite resin group a uniform layer of primer was applied onto the tooth surface with a disposable brush (KGbrush, Cotia, Brazil), followed by a light jet of air for 5 seconds. A small amount of resin was applied to the base of the bracket, which was immediately placed on the tooth surface and light-cured. For the resin-modified glass ionomer, the powder and the liquid were mixed in a proportion of 1 measure of powder for two drops of liquid. The cement was mixed for 20 to 25 seconds on a glass plate using a spatula (spatula n. 24, Duflex, SS White, Rio de Janeiro, Brazil). A portion of this mixture was placed at the base of the bracket, which was positioned onto the tooth surface and light-cured.

The brackets were positioned onto the most central and flat portion of the buccal surface. Light manual pressure was applied and the excess cement was removed with a dental probe (exploratory probe n. 47, Duflex, SS White, Rio de Janeiro, Brazil). Light curing was performed using a halogen light curing unit (Demetron, LC Kerr Corporation, Orange, California, USA) for 40 seconds, 10 seconds on each side of the tooth (incisal, cervical, distal and mesial). Irradiance was measured every five brackets using a radiometer system (Newdent Equipment Ltd, Ribeirão Preto, SP, Brazil). The average irradiance was measured at $483 \mathrm{~mW} / \mathrm{cm}^{2}$.

The teeth were stored in distilled water in an incubator (Odontobrás ECB1.3 Digital, Ribeirão Preto, Brazil) at $37^{\circ} \mathrm{C}$ for 24 hours. The specimens were then randomly divided into eight groups according to the number of thermal cycles (Table 1).

The number of thermal cycles $(1000,2000$ and 3000) was defined according to those commonly used in the literature, simulating aging for less than a year ${ }^{16-}$ 18, whereby 10,000 (ten thousand) cycles corresponded to one year of aging ${ }^{19}$. A thermocycling equipment was used (Elquip, São Carlos, Brazil) set at 15-second dips to 5 seconds of transfer time. The immersion temperatures ranged from $5^{\circ} \mathrm{C}$ to $55^{\circ} \mathrm{C}$. At the end of the thermocycling period, the shear bond strength tests were performed.
Table 1. Groups studied according to orthodontic bonding materials and number of cycles.

\begin{tabular}{cccc}
\hline Groups & $\begin{array}{c}\text { Number of } \\
\text { Teeth }\end{array}$ & Sticking materials & $\begin{array}{c}\text { Number of thermal } \\
\text { cycles }\end{array}$ \\
\hline 1 & 10 & Transbond XT & none (control) \\
2 & 10 & Fuji Ortho LC & none (control) \\
3 & 10 & Transbond XT & 1000 cycles \\
4 & 10 & Fuji Ortho LC & 1000 cycles \\
5 & 10 & Transbond XT & 2000 cycles \\
6 & 10 & Fuji Ortho LC & 2000 cycles \\
7 & 10 & Transbond XT & 3000 cycles \\
8 & 10 & Fuji Ortho LC & 3000 cycles \\
\hline
\end{tabular}

The test specimens were taken to a universal testing machine (Emic DL2000, São José dos Pinhais, Brazil) for shear bond strength testing. A chisel-type tip was chosen to apply force to the contact interface between the orthodontic bracket and the enamel surface at a speed of $0.5 \mathrm{~mm}$ per minute. A digital caliper (Mitutoyo MIP / E 103, Suzano, Brazil) was used to measure the width and height of the metal bracket to calculate the bonding area between the material and the enamel. This area measured $10,88 \mathrm{~mm}^{2}$.

Bond strength value was calculated according to the following formula 6 : $R=F / A$, where:

$\mathrm{R}$ : corresponded to the shear strength in Megapascal (MPa);

$\mathrm{F}$ : was the load required to break the tooth-resinbracket bond;

A: corresponded to the bonding area, represented by the bracket base area $\left(10.88 \mathrm{~mm}^{2}\right)$.

Upon failure, the specimens were examined under a stereoscopic loupe (eikonal, São Paulo, Brazil) at 10 times magnification to define the adhesive remnant index (ARI). For the classification of the ARI, the following scores were used: $0=$ no material adhered to the tooth; $1=$ less than half the material adhered to the tooth; $2=$ more than half the material adhered to the tooth and $3=$ all the material adhered to the tooth, including the bracket mesh imprint. 
ARI assessment was performed by a calibrated examiner with experience in this type of methodology.

Data homogeneity was verified using the ShapiroWilk test, given the assumptions for parametric statistical analysis. Bond strength data were evaluated using twoway analysis of variance (ANOVA). The ARI was displayed as a table containing median values and a graph showing distribution frequencies. The differences between the groups were analyzed using the Kruskal-Wallis test. The significance level was 5\%, using the Minitab 16 program for the implementation of statistical calculations.

\section{RESULTS}

The two-way ANOVA showed no significant interaction between the factors material for bracket bonding to enamel and number of thermal cycles ( $p=$ 0.439). No difference in bond strength was observed between brackets and the enamel in terms of the number of thermal cycles to which the specimens were submitted $(p=0.873)$. A significant difference in bond strength was observed between the materials for brackets bonding ( $p$ $=0.022$ ), where the higher values were obtained for the composite resin Transbond XT, regardless of the number of thermal cycles, as illustrated in Table 2.

Table 2. Mean and standard deviation of the shear bond strength values (MPa), in terms of the adhesive system used and number of thermal cycles

\begin{tabular}{cccc}
\hline Thermal cycling & Transbond XT & Fuji Ortho LC & Overall mean \\
\hline 0 & $17.59(6.34)$ & $17.82(4.02)$ & $17.71(5.17)$ * \\
1000 & $19.53(7.84)$ & $14.26(6.37)$ & $17.03(7.49)$ * \\
2000 & $18.74(9.81)$ & $14.54(5.37)$ & $16.64(8.00)$ * \\
3000 & $17.85(5.06)$ & $14.46(5.92)$ & $16.16(5.63)$ * \\
\hline Overall mean & $18.37(7.22)$ A & $15.30(5.46)$ B & - \\
\hline
\end{tabular}

Note: Mean followed by different letters indicate significant difference. Overall mean with an asterisk indicate no difference.

The Kruskal Wallis test showed no significant difference between groups ( $p=0.6619)$ and the ARI (Table 3 ).

Table 3. Median and Kruskal Wallis test result for the adhesive remnant index, according to the adhesive system used and number of thermal cycles.

\begin{tabular}{cc}
\hline Group & Median \\
\hline Transbond - control & 1 \\
Fuji Ortho - control & 0.5 \\
Transbond - 1000 cycles & 0 \\
Fuji Ortho - 1000 cycles & 0 \\
Transbond - 2000 cycles & 0 \\
Fuji Ortho - 2000 cycles & 0 \\
Transbond - 3000 cycles & 0 \\
Fuji Ortho - 3000 cycles & 1 \\
\hline
\end{tabular}

Figure 1 illustrates the percentage of scores for the ARI, according to the adhesive system and number of thermal cycles. In $40-80 \%$ of the specimens from all the experimental conditions, no adhesive remained on the tooth structure (score 0), except when the adhesive system with composite resin Transbond XT was not thermocycled and when the Fuji Ortho LC material was subjected to 3000 cycles, where there was a higher percentage of the ARI score 1, i.e., less than half the adhesive remained on the tooth structure. ARI score 1 was observed in all groups, representing $20-60 \%$ of the shear bond strength test failures.

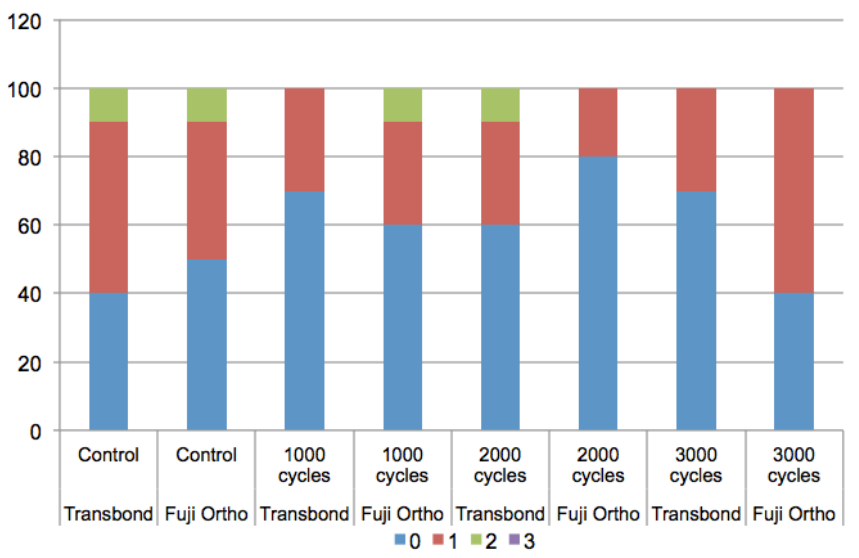

Figure 1. Bar chart showing the percentage of scores obtained for the adhesive remnant index, according to the adhesive system and number of thermal cycles.

In $10 \%$ of specimens bonded with Transbond XT or Fuji Ortho LC and not thermocycled, the presence of more than half of the adhesive was observed on the tooth surface (score 2). In no experimental condition was the adhesive fully retained on the enamel.

\section{DISCUSSION}

Thermocycling, among many methods, is considered a valid approach to simulate material aging in vitro $7,9-10,13,17$; however, there is no consensus in the literature on the number of cycles, temperature or immersion times ${ }^{9-10}$. Therefore, estimates of values close to in vivo conditions are extremely varied and the choice of such parameters is commonly based on convenience ${ }^{7,9-10}$. In a literature review by Morresi et al. ${ }^{10}$, it was concluded that authors barely offer a rationale for the choice of temperature and, due to the great variability of cycles, temperature, immersion time and intervals between immersions, the data become practically incomparable. 
In this study, the samples were submitted to 1000, 2000 and 3000 thermal cycles, with immersion temperatures between $5^{\circ} \mathrm{C}$ and $55^{\circ} \mathrm{C}$, 15-second dips and a 5-second interval between immersions, in order to allow comparisons with other studies that used similar conditions ${ }^{7,12,14-15,17}$. In addition, the simulated aging corresponded to less than a year, since 10,000 (ten thousand) cycles would be needed to simulate one year of aging ${ }^{19}$, which poses great difficulties in terms of laboratory testing, since this would require months to be achieved.

The results showed no significant effect of the number of thermal cycles and materials used for bracket bonding, nor was there any difference in bond strength between brackets and enamel in terms of the number of thermal cycles within the same bonding material group. These results are similar to those found by Aguilar et al. ${ }^{17}$ who noted that 3000 thermal cycles between $5^{\circ} \mathrm{C}$ and $55^{\circ}$ $\mathrm{C}$ and intermediate temperature of $37^{\circ} \mathrm{C}$ did not affect the bond strength of the materials used (Scotchbond MP, OptiBond FL, Amalgambond Plus and OptiBond dual cure). These authors suggested that the most important factor in material degradation could be the water, since no difference in bond strength was observed between the thermocycled and water-stored control specimens. Furthermore, they stated that water absorption during thermocycling may counterbalance the shrinkage caused by polymerization, thus reducing shrinkage stress, which could lead to bond failure ${ }^{17}$.

The resin matrix of the composite resin absorbs less water than glass ionomer and is more resistant to hydrolytic degradation for being less hydrophilic and absorbing less water over time ${ }^{20}$. Furthermore, glass ionomer cements feature rapid water imbibition in addition to leaching several components, such as organic molecules, silicate, fluoride, calcium and other ions ${ }^{8}$. However, another factor to be considered is temperature fluctuation, to which the specimens were subjected, as well as the distinct linear thermal expansion coefficients of the materials used. It is known that differences between thermal expansion coefficient of the tooth substrate and the material can result in detachment and gap formation, where glass ionomer holds an advantage over resin as it has a linear thermal expansion coefficient closer to that of the enamel ${ }^{21}$. Another factor to consider is fatigue, where the influence of occlusal loads in a clinical situation could lead to further degradation, reducing bond strength values.

This study also found a statistically significant difference in bond strength values between the bonding materials tested, with higher values observed for the composite resin Transbond XT, regardless of the number of thermal cycles. This finding corroborates those by other studies, independently of whether a thermal cycling step was included or not 22-23. Nonetheless, other studies have reported no difference between these materials ${ }^{4,23}$. Moreover, it has been demonstrated that a bonding strategy such as prior conditioning of the enamel surface or the use of a self-etching primer demonstrated significant difference in bond strength values ${ }^{11,24-26}$. It has been speculated that lower bond strength values should be observed when a modified glass ionomer is used without etching the enamel prior to bracket bonding, which has been considered a relevant factor that could affect the performance of this material, which adheres to enamel chemically and hence bond strength values are not of the same magnitude as those observed for composites ${ }^{27}$.

Glass ionomer has been demonstrated to yield lower bond strength values than composites in vitro $^{22-23}$ and, therefore, its use has been questioned. Nevertheless, the performance of this material in vivo has been shown to be comparable to those of composites with regards to adhesion and failure rates ${ }^{4,23}$ and with the potential advantage of inhibiting demineralization around orthodontic brackets ${ }^{3,28}$. It should be highlighted that a classic study by Reynolds ${ }^{29}$ reported that clinically acceptable bond strength values should range between 6 and $8 \mathrm{MPa}$. The values obtained in this study exceeded those figures, thus enabling both materials to be indicated for bracket bonding. Furthermore, the ARI values were not accompanied by the presence of bonding material to the tooth, thus potentially preserving tooth substrate by avoiding the need to remove adhered resin.

Considering that the mean bond strength values observed in this study were higher than those regarded as clinically acceptable and that both materials showed low levels of adhesive residue, they could both be used in orthodontic practice to bond orthodontic brackets to enamel.

\section{CONCLUSION}

The number of thermal cycles did not influence the bond strength of the adhesive materials investigated. Moreover, the composite resin Transbond XT showed higher bond strength than the resin-modified glass ionomer Fuji Ortho $L C$, regardless of the number of thermal cycles. Regarding the adhesive remnant index, most specimens from all groups had no adhesive residue on the tooth after bracket removal. 


\section{REFERENCES}

1. Gama AC, Moraes AG, Yamasaki LC, Loguercio AD, Carvalho CN, Bauer J. Properties of composite materials used for bracket bonding. Braz Dent J. 2013;24(3):279-83. doi:10.1590/01036440201302184

2. Cacciafesta V, Sfondrini MF, De Angelis M, Scribante A, Klersy C. Effect of water and saliva contamination on shear bond strenght of brackets bonded with conventional, hydrophilic, and self-etching primers. Am J Orthod Dentofacial Orthop. 2003;123(6):633-40.

3. Pascotto RC, Navarro MF, Capelozza Filho L, Cury JA. In vivo effect of a resin-modified glass ionomer cement on enamel demineralization around orthodontic brackets. Am J Orthod Dentofacial Orthop. 2004;125(1):36-41.

4. Rosenbach G, Cal-Neto JP, Oliveira SR, Chevitarese O, Almeida MA. Effect of enamel etching on tensile bond strength of brackets bonded in vivo with a resin-reinforced glass ionomer cement. Angle Orthod. 2007;77(1):113-6. doi:10.2319/111705402R.1

5. Bishara SE, VonWald L, Laffoon JF, Warren JJ. The effect of repeated bonding on the shear bond strength of a composite resin orthodontic adhesive. Angle Orthod. 2000;70(6):43541.

6. Romano FL, Valério RA, Gomes-Silva JM, Ferreira JT, Faria $\mathrm{G}$, Borsatto $M C$. Clinical evaluation of the failure rate of metallic brackets bonded with orthodontic composites. Braz Dent J. 2012;23(4):399-402. doi:10.1590/S010364402012000400015

7. Guzman UA, Jerrold L, Vig PS, Abdelkarim A. Comparison of shear bond strength and adhesive remnant index between precoated and conventionally bonded orthodontic brackets. Prog Orthod. 2013;14:39. doi:10.1186/2196-1042-14-39

8. Fano L, Fano V, Ma W, Wang X, Zhu F. Hydrolytic degradation and cracks in resin-modified glass-ionomer cements. J Biomed Mater Res B Appl Biomater. 2004;69(1):87-93.

9. Amaral FLB, Colucci V, Palma-Dibb RG, Corona SAM. Assessment of in vitro methods used to promote adhesive interface degradation: a critical review. J Esthet Restor Dent. 2007;19(6):340-54

10. Morresi AL, D'Amario M, Capogreco M, Gatto R, Marzo G, $D^{\prime}$ Arcangelo $C$, et al. Thermal cycling for restorative materials: does a standardized protocol exist in laboratory testing? A literature review. J Mech Behav Biomed Mater. 2014;29:295308. doi:10.1016/j.jmbbm.2013.09.013

11. Bishara SE, VonWald L, Laffoon JF, Warren JJ. Effect of a self-etch primer/adhesive on the shear bond strength of orthodontic brackets. Am J Orthod Dentofacial Orthop. 2001 Jun;119(6):621-4.

12. Bishara SE, Ostby AW, Laffoon JF, Warren J. Shear bond strength comparison of two adhesive systems following thermocycling. A new self-etch primer and a resin-modified glass ionomer. Angle Orthod. 2007:77(2):337-41. doi:10.2319/00033219(2007)077[0337:SBSCOT]2.0.CO;2
13. Coreil MN, McInnes-Ledoux P, Ledoux WR, Weinberg R. Shear bond strenght of four orthodontic bonding systems. Am J Orthod Dentofac Orthop. 1990;97(2):126-9.

14. Yuasa T, lijima M, Ito S, Muguruma T, Saito T, Mizoguchi I. Effects of long-term storage and thermocycling on bond strength of two self-etching primer adhesive systems. Eur J Orthod. 2010;32(3):285-90. doi:10.1093/ejo/cjp118

15. Mirzakouchaki B, Kimyai S, Hydari M, Shahrbaf S, Mirzakouchaki-Boroujeni P. Effect of self-etching primer/ adhesive and conventional bonding on the shear bond strength in metallic and ceramic brackets. Med Oral Patol Oral Cir Bucal. 2012;17(1):e164-70. doi:10.4317/medoral.17024

16. Crim GA, Swartz ML, Phillips RW. Comparison of four thermocycling techniques. J Prosthet Dent. 1985;53(1):50-3.

17. Aguilar LT, Rezende NPM, Reis A, Loguercio AD, Grande RHM, Ballester RY, et al. Tensile bond strenght of adhesive systems - effects of primer and thermocycling. Pesqui Odontol Bras. 2002;16(1):37-42. doi:10.1590/S1517-74912002000100007

18. Pazinatto FB, Campos BB, Costa LC, Atta MT. Effect of the number of thermocycles on microleakage of resin composite restorations. Pesqui Odontol Bras. 2003;17(4):337-41. doi: 10.1590/S1517-74912003000400008

19. Gale MS, Darvell BW. Thermal cycling procedures for laboratory testing of dental restorations. J Dent. 1999;27(2):89-99.

20. de Paula $A B$, de Fúcio $S B$, Alonso RC, Ambrosano GM, Puppin-Rontani RM. Influence of chemical degradation on the surface properties of nano restorative materials. Oper Dent. 2014;39(3):E109-17. doi:10.2341/12-340

21. Sidhu SK, Carrick TE, McCabe JF. Temperature mediated coefficient of dimensional change of dental tooth-colored restorative materials. Dent Mater. 2004;20(5):435-40.

22. Haydar B, Sarikaya S, Çehreli ZC. Comparison of shear bond strenght of three bonding agents with metal and ceramic brackets. Angle Orthod. 1999;69(5):457-62.

23. Summers A, Kao E, Gilmore J, Gunel E, Ngan P. Comparison of bond strength between a conventional resin adhesive and a resin-modified glass ionomer adhesive: an in vitro and in vivo study. Am J Orthod Dentofacial Orthop. 2004;126(2):200-6.

24. Bishara SE, Ajlouni R, Laffoon JF, Warren JJ. Effect of a fluoridereleasing self-etch acidic primer on the shear bond strenght of orthodontic brackets. Angle Orthod. 2002;72(3):199-202.

25. Shinya M, Shinya A, Lassila LV, Gomi H, Varrela J, Vallittu PK, et al. Treated enamel surface patterns associated with five orthodontic adhesive systems--surface morphology and shear bond strength. Dent Mater J. 2008;27(1):1-6.

26. Horiuchi S, Kaneko K, Mori H, Kawakami E, Tsukahara T, Yamamoto $K$, et al. Enamel bonding of self-etching and phosphoric acid-etching orthodontic adhesives in simulated clinical conditions: debonding force and enamel surface. Dent Mater J. 2009;28(4):419-25. doi:10.4012/dmj.28.419

27. Iliadi A, Baumgartner S, Athanasiou AE, Eliades T, Eliades G. Effect of intraoral aging on the setting status of resin composite and 
glass ionomer orthodontic adhesives. Am J Orthod Dentofacial Orthop. 2014;145(4):425-33. doi:10.1016/j.ajodo.2013.11.020

28. Santos RL, Pithon MM, Fernandes AB, Carvalho FG, Cavalcanti $A L$, Vaitsman DS. Fluoride release/uptake from different orthodontic adhesives: a 30-month longitudinal study. Braz Dent J. 2013;24(4):410-4. doi:10.1590/0103-6440201302239
29. Reynolds IR. Letter: composite filling materials as adhesive in orthodontics. Br J Orthod. 1975 feb;138(3):83. doi:10.1038/ sj.bdj.4803387

Received on: 10/8/2014

Final version resubmitted on: 18/11/2014

Approved on: 4/12/2014 
